\title{
aniki
}

Revista Portuguesa da Imagem em Movimento

Portuguese Journal of the Moving Image

\section{Yvone Kane e as representações do passado africano} Alexsandro de Sousa e Silva ${ }^{1}$

Mostra África(s). Cinema e revolução: as independências de Angola, GuinéBissau e Moçambique, em filmes de luta e memória no Caixa Belas Artes (São Paulo, 10 a 23 de novembro de 2016).

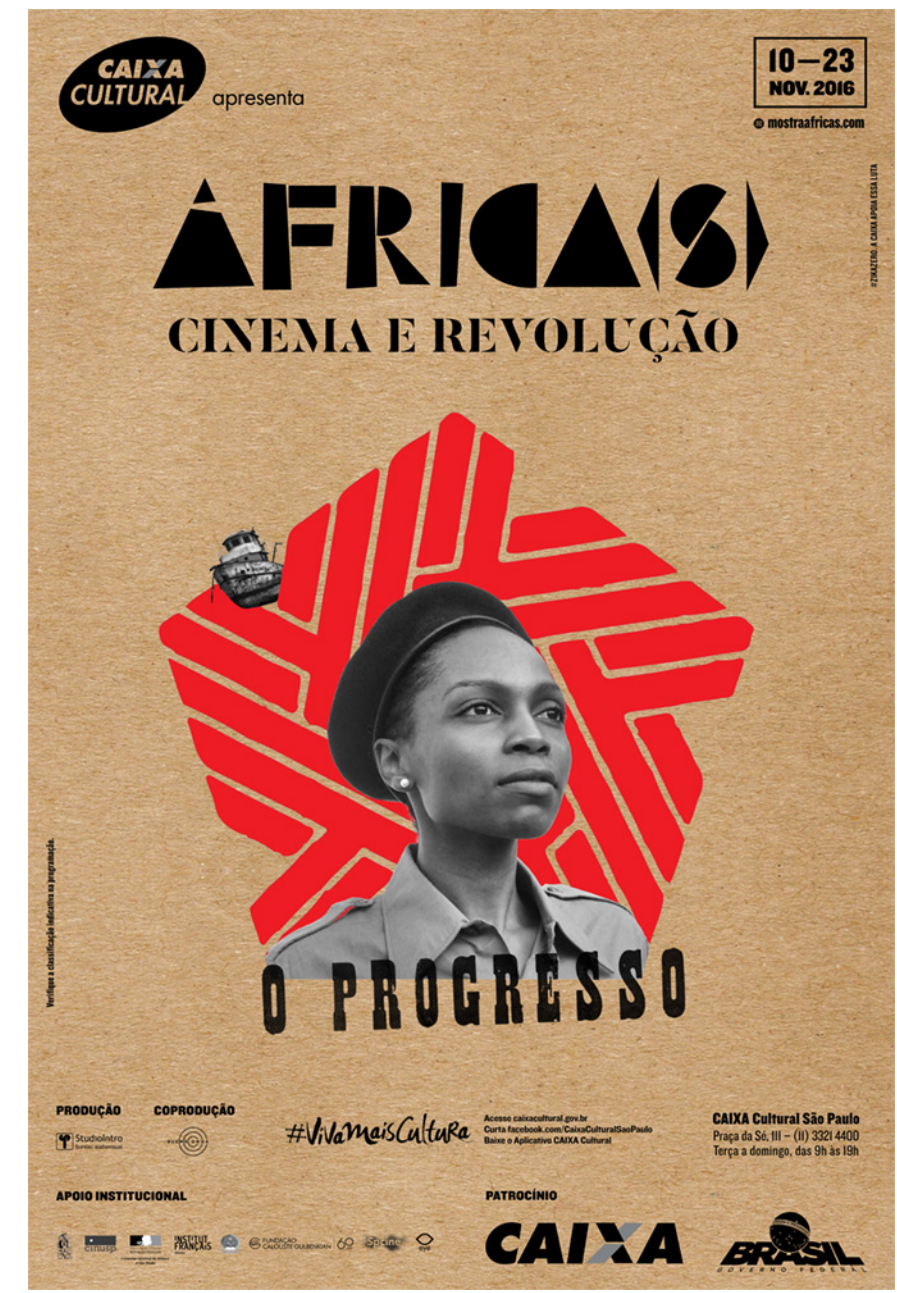

Imagem 1: Cartaz de divulgação da mostra | (c) Arte: Fernando Naigeborin sobre fotograma do filme Yvone Kane (Margarida Cardoso, 2014)

O cartaz da mostra África(s), cinema e revolução exibe-nos o retrato de uma mulher fardada, na verdade uma personagem, Yvone Kane (Mina Andala). Esta imagem foi retirada do filme homônimo da realizadora portuguesa Margarida Cardoso, de 2014, um dos que foram exibidos no evento em duas sessões. A mesma imagem estampa a

\footnotetext{
${ }^{1}$ Universidade de São Paulo, Faculdade de Filosofia, Letras e Ciências Humanas, 05508-010, São Paulo, Brasil. 
capa do catálogo do evento, uma importante referência bibliográfica, pois contém uma série de artigos relevantes sobre os filmes exibidos. Na película, Yvone Kane é uma misteriosa militante do principal partido político de um determinado país africano (uma mescla de Angola e Moçambique), que descobre um caso de corrupção envolvendo comércio ilegal de armas. Mais tarde, Kane foge do país e é assassinada na Inglaterra. Tudo ocorreu no passado; dela, só restam memórias, imagens e documentos. A busca pelas razões de sua morte é o leitmotiv que impulsiona a narrativa de Yvone Kane. Da mesma forma que o filme, a mostra também levou o público a mergulhar nas contradições do passado de Angola, Moçambique e Guiné-Bissau através de uma rica e variada filmografia. ${ }^{2}$

A mostra África(s). Cinema e revolução ${ }^{3}$ foi realizada em São Paulo no mês da "consciência negra," assim chamado devido ao Dia Nacional de Zumbi e da Consciência Negra, celebrado a 20 de novembro, data atribuída à morte do líder quilombola Zumbi dos Palmares (1655-1695) pelo grupo bandeirante de Domingos Jorge Velho no final do século XVII. A crescente reivindicação social das matrizes africanas de identidade nas últimas décadas e o conturbado momento político nacional e internacional formam o pano de fundo que faz do evento um espaço necessário e oportuno para afirmação de identidades e de debates acerca das construções visuais do passado no continente africano e no Brasil.

A curadoria da mostra ficou a cargo da pesquisadora de cinema Lúcia Ramos Monteiro que, com a ajuda da produtora Natalia Barrenha, teve a sensibilidade de reunir um conjunto de filmes exibidos de maneira que seus significados confluíssem e interagissem entre si. Como se não bastasse a interessante lista de trinta e nove filmes (entre curtas, longas e cinejornais), a qual comentaremos adiante, Lúcia Monteiro e Natalia Barrenha trouxeram ao evento pesquisadoras e pesquisadores do cinema e, em especial, nomes importantes do cinema na África, como os cineastas Flora Gomes, Ruy Guerra e Camilo de Sousa, a cineasta Isabel Noronha, e a filha de Sarah Maldoror, Annouchka de Andrade, que comentou a trajetória e a obra da mãe em algumas sessões. Por fim, eventos como debates, mesas redondas e oficinas aproximaram cineastas, pesquisadores e público, para ajudar a melhor compreender os cinemas africanos. A principal contribuição orçamentária para a realização da mostra veio de um projeto do banco estatal Caixa Econômica Federal.

A organização do evento fez um grande esforço para expor ao público filmes raros e inacessíveis até mesmo para os especialistas, além de obras recentes que abordam, direta ou indiretamente, o período das independências de Angola, Moçambique e Guiné-Bissau.

\footnotetext{
${ }^{2}$ Vale recordar que Angola, Moçambique e Guiné-Bissau, juntamente com Cabo Verde e São Tomé e Príncipe, conquistaram a independência de Portugal entre 1973 (Guiné-Bissau, unicamente) e 1975 (os demais países).

${ }^{3}$ http://www.mostraafricas.com/
} 
Dessa forma, quebrou-se uma parte da enorme barreira que impede que o cinema feito em ou sobre a África chegue ao Brasil. Dentre as obras raras, destacamos 25, dirigido em 1975 pelos brasileiros Celso Luccas e José Celso Martinez Corrêa (mítico "tropicalista” do Teatro Oficina), um dos primeiros documentários realizados em Moçambique logo após a independência. A cena da multidão esperando o primeiro amanhecer em Maputo após a declaração da autonomia nacional deverá ainda estar na memória dos espectadores e espectadoras. Outro filme raro apresentado na mostra foi Morte negada (1988), do guineense Flora Gomes, que encena o processo de luta pela independência do país e a organização do Estado pela perspectiva de uma jovem mulher, Diminga, e de seu amor, o guerrilheiro Sako. A exibição de Sambizanga (1972) e a posterior intervenção de Annouchka de Andrade constituíram um dos grandes momentos da mostra. A obra se destaca pela forte consistência e dramaticidade da narrativa, pela beleza plástica das imagens e pela formidável trilha musical; por seu lado, a fala de Annouchka sobre a cineasta Sarah Maldoror realçou a importante trajetória de uma mulher negra filmando em terras africanas e a luta de sua filha em preservar os filmes para as futuras gerações.

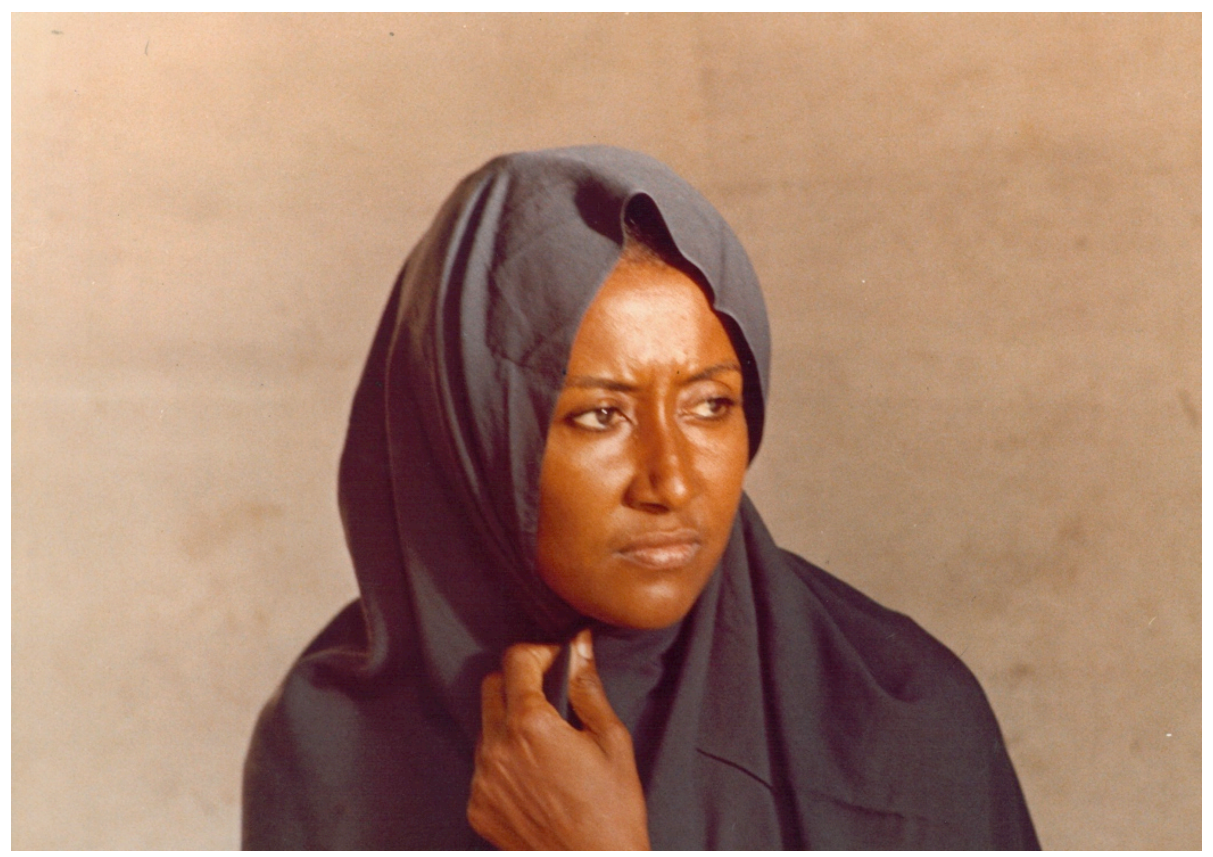

Figura 2: Imagem de Maria (Elisa Andrade) em Sambizanga (Sarah Maldoror, 1972) | (C) Divulgação

Da filmografia recente, destacamos os provocadores curtasmetragens do francês Mathieu Kleyebe Abonnenc Prefácio a Fuzis para Banta (2011), Um filme italiano. África, adeus! (2012) e Tudo bem, tudo bem, vamos continuar (2013), que investigam diversas questões como, por exemplo, a exploração europeia na África. Em Prefácio..., através de fotografias de cena e das memórias de Sarah 
Maldoror, o diretor buscou reconstituir o enredo de Fuzis para Banta (1970), filme perdido da cineasta, evidenciando uma importante parceria entre diferentes gerações de artistas. Flora Gomes, com $A$ República dos Meninos (2012), trouxe uma alegórica superação da violência e do individualismo numa fábula rejuvenescedora. Por fim, os filmes da cineasta portuguesa Margarida Cardoso Kuxa Kanema, o nascimento do cinema (2003) e o já mencionado Yvone Kane (2014) apresentam visões críticas e questionadoras sobre a construção do Estado nacional em Moçambique e em Angola.

Os breves comentários acima sobre a filmografia da mostra evidenciam que a organização não buscou apenas produções estritamente produzidas por artistas da África de língua portuguesa e expôs o lado mais importante de uma cinematografia: as trocas de impressões entre diferentes culturas. Por esse motivo, encontramos na mostra filmes brasileiros (4), portugueses (7), cubanos (5), franceses (3), holandeses (3) e principalmente de Angola (3), Moçambique (10) e Guiné-Bissau (4). Vale recordar que as sessões ocorreram majoritariamente na sala 4 (Aleijadinho) do cinema Caixa Belas Artes, espaço recém-reconquistado na cidade de São Paulo graças à mobilização social que requereu a intervenção da Prefeitura na manutenção do espaço. Além do Belas Artes, houve algumas sessões no Cine Olido e no Cinusp.

Para comentar a filmografia da mostra, foram convidados pesquisadores e cineastas. Celso Luccas comentou a sessão de 25, recordando as filmagens por Moçambique em 1975, o acesso a imagens do período do colonialismo português e a circulação do filme pelo Brasil da ditadura militar. A professora e pesquisadora da Universidade Estadual de Campinas (UNICAMP) Vavy Pacheco Borges fez observações sobre a vida e obra de Ruy Guerra, sobre o qual está elaborando uma biografia, Ruy Guerra: paixão escancarada (Boitempo, 2017, no prelo). A cineasta e também investigadora acadêmica Raquel Schefer exibiu e falou sobre os dois curtas de sua autoria, Avó (Muidumbe, 2009) e O jogo (Nshajo, 2010), filmes em que mobilizou materiais do seu arquivo familiar, vinculado à presença portuguesa em Moçambique no período colonial. Da mesma forma, o diretor Mathieu Kleyebe Abonnenc expôs seus heterodoxos curtas metragens e respondeu às questões do público, pois sua filmografia é interessantemente provocadora por colocar mais questões aos espectadores e espectadoras do que respostas. Em uma das sessões, Abonnenc foi acompanhado da pesquisadora Emi Koide, que trabalha com arte contemporânea africana. Como a organização da mostra procurou aproximar os dois lados do Atlântico, Alexsandro Silva e Cristina Beskow, especialistas em cinema latino-americano, ${ }^{4}$

\footnotetext{
${ }^{4} \mathrm{O}$ autor desta resenha estuda as relações políticas, militares e audiovisuais entre Cuba e países africanos entre 1959 e 1991. Os noticieros (cinejornais) e documentários cubanos exibidos na Mostra estão entre as fontes históricas selecionadas para análise: Maputo, meridiano novo (Santiago Álvarez, 1976, Moçambique/Cuba),
} 
comentaram as sessões que exibiram curtas metragens cubanos assinados por Santiago Álvarez, Daniel Díaz Torres e Miguel Torres nos anos 1970 e $1980 .^{5}$ O moçambicano Camilo de Sousa analisou seu trabalho ao lado de Zdravko Velimorovic em O tempo dos leopardos (1985). Annouchka de Andrade, conforme comentamos acima, falou da obra de Sarah Maldoror e, por fim, o diretor Flora Gomes fez intervenções junto ao público em duas oportunidades. A longa descrição das participações expõe a saudável preocupação da mostra em aproximar dos espectadores e espectadoras não apenas os filmes, mas também acadêmicos, acadêmicas, diretores e diretoras.

Outras atividades reforçaram esses laços entre especialistas e público. A mesa redonda sobre cinema moçambicano com Ruy Guerra, José Luis Cabaço, Camilo de Sousa e Isabel Noronha teve mediação da professora e pesquisadora Rita Chaves. Realizaram-se também as oficinas "Memória e Audiovisual I: Filmes de segunda mão ou a reapropriação de arquivos familiares" com a cineasta portuguesa Raquel Schefer, e "Memória e Audiovisual II: O conceito de cada da memória negra: Cinema expandido e história da preservação e divulgação da memória negra local," com a diretora Lilian Solá Santiago, ambas na Caixa Cultural Sé, importante espaço cultural da cidade de São Paulo. Enfim, Flora Gomes não apenas comentou seus filmes após duas sessões, como também participou num debate programado com a professora da Universidade Federal de São Paulo (UNIFESP) Carolin Overhoff Ferreira. A energia da organização permitiu uma oficina não programada na Escola de Comunicação e Artes da Universidade de São Paulo (ECA-USP), onde o realizador falou sobre seus filmes e a sua experiência como cineasta africano.

O público, tímido no começo da mostra, aos poucos se mostrou mais presente nas sessões e atividades. Em alguns debates os ânimos se exaltaram, certamente devido à complexidade da mostra e às diferentes demandas sociais pelas heranças africanas, numa sociedade com elevados graus de racismo. A escolha da organização em não legendar as falas em língua portuguesa foi comprovadamente acertada, pois a opção contrária visaria acentuar o estranhamento que há nos brasileiros e brasileiras sobre as oralidades portuguesas e africanas. Assim, o público fez o esforço em superar as dificuldades de entendimento e acompanhou os filmes.

Ao contrário do final do filme Yvone Kane, em que a busca pela misteriosa guerrilheira parece terminar numa melancolia pro-

Nova sinfonia (Santiago Álvarez, 1982, Moçambique/Cuba), O milagre da terra morena (Noticiero ICAIC Latinoamericano, n. 663, Santiago Álvarez, 1974, Portugal/Guiné-Bissau/Cuba) e os Noticieros ICAIC Latinoamericano n. 736 (Daniel Díaz Torres, 1975, Cuba) e 739 (Miguel Torres, 1975, Cuba).

${ }^{5}$ Lembramos que Emi Koide escreveu no catálogo da mostra um texto sobre a obra de Mathieu Kleyebe Abonnenc, "Impasses da descolonização: imagens, fantasmas e detritos imperiais," e que Cristina Beskow assinou o artigo sobre Santiago Álvarez, "Miradas anti-coloniais de Santiago Álvarez em Moçambique." 
funda na qual a protagonista Rita (Beatriz Batarda) conclui sua investigação isolada e sem referências, a mostra África(s). Cinema e revolução expôs as vantagens em aproximar o público junto a filmes, diretores, diretoras, acadêmicos, pesquisadores e demais interessados e interessadas, transformando a oportunidade em um espaço privilegiado de intercâmbio de ideias, imagens e sons que certamente estará na memória de muitos participantes. 